\title{
COPIM
}

\section{One year of COPIM! The story so far}

\section{Lucy Barnes}

Published on: Nov 11, 2020

DOI: $10.21428 / 785 a 6451.7 a 4 a 30 a e$

License: $\underline{\text { Creative Commons Attribution } 4.0 \text { International License (CC-BY 4.0). }}$. 


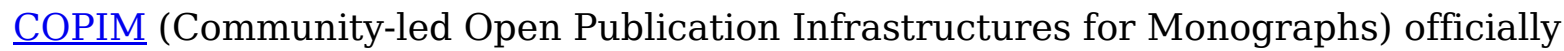
began its work one year ago on 1 November 2019. Funded by Research England and Arcadia Fund, COPIM is an international partnership of researchers, universities, librarians, open access book publishers and infrastructure providers who are building community-owned, open systems and infrastructures to enable open access book publishing to flourish.

The project is funded for three years, and this is a summary of our first year of activities. Read on for our major outputs, key challenges, impact, and individual Work Package updates.

N.B. The main page of our Open Documentation site is organised by quarters, so, if you prefer, you can browse our outputs and announcements as they happened. We have also published a public version of our full Annual Report to our funders, if you want to dig into a more detailed summary.

\section{Major Outputs}

During the first year of the project, COPIM has established a solid foundation in collaborative research, infrastructure development, project management, and outreach and community building. Successfully adapting our approach to face a set of unforeseen challenges, we have fostered engagement with librarians, publishers, authors, technology providers and the general public, bringing together key experts and those interested in learning more about scholar-led not-for-profit OA book publishing.

COPIM's work packages have predominantly engaged in community building and collected research data, conducting landscape studies by means of several scoping reports and consulting stakeholders via workshops and participation in external events. All of this is in preparation and support of the infrastructures, the pilot cases, and the governance and preservation structures that will be developed in Years 2 and 3 of the project.

In parallel, the project has been developing its underlying philosophy and organisational principle of 'scaling_small', which informs its overall work, engaging the work packages in a dialogue around how this can be implemented and put into practice. 
The main results achieved during COPIM's first year include:

- the publication of two major scoping reports, comprising:

- the WP3 Scoping Report Revenue Models for Open Access Monographs, published in September 2020, which provides a concise analysis of the open access economic models in use today in scholarly publishing;

- and the WP5 Scoping Report Building an Open Dissemination System, published in July 2020, which discusses the distribution of books via the traditional library supply chain and new forms of digital dissemination before looking at metadata in depth, with metadata creation and types being investigated in order to form a number of key recommendations for WP5;

- the successful organisation and documentation of eleven workshops engaging with more than 120 national and international stakeholders from the UK, the US, Africa, Latin America, Australia, New Zealand, and Europe to establish communities on a variety of overarching open access book-related topics;

- the initial setup and continuous further development of an $\underline{\text { Open Dissemination }}$ System, a resource to make open access book metadata available in an open and transparent way, which will integrate into the larger Open Dissemination System, to be developed in Years 2 and 3.;

- the launch of an innovative revenue model to fund open access monographs at a traditional scholarly publisher: Opening The Future. Building on library subscription initiatives like those in use at Open Book Publishers and punctum books, this is a sustainable OA publishing model being piloted as a COPIM case study in partnership with the Central European University Press;

- and the setup and iterative extension of a set of Outreach and Dissemination activities that are combining a variety of channels including social media and open community platforms.

In addition to the workshops organised by COPIM, the team has also supported and contributed to events and workshops held by external stakeholders and organisations working towards shared goals (following the previously mentioned principle of 'scaling small'). These organisations include:

- Invest in Open Infrastructure's Future of Scholarship project;

- Knowledge Futures Group's Community Summit;

- OASPA;

- OPERAS;

- LIBER; 
- the Next Generation Libraries Project;

- The British Library;

- OpenAIRE, $\underline{\text { COAR, and EIFL; }}$

- and the Open Access Books Network platform.

COPIM has also set up new collaborations to build innovative forms of open online community events, evident from the team's work with the Coko Foundation in creating the Open Publishing Fest. In two exciting weeks that were filled with more than 150 events, Open Publishing Fest allowed COPIM members and the larger scholarly communications community to discover new formats to share their ongoing work with a more global audience, and presented an opportunity to expand COPIM's community to those not only working in scholarship but also in open source software development, open government, and the arts.

[For a full list of activities and outputs in Year 1, please see the Annual Report]

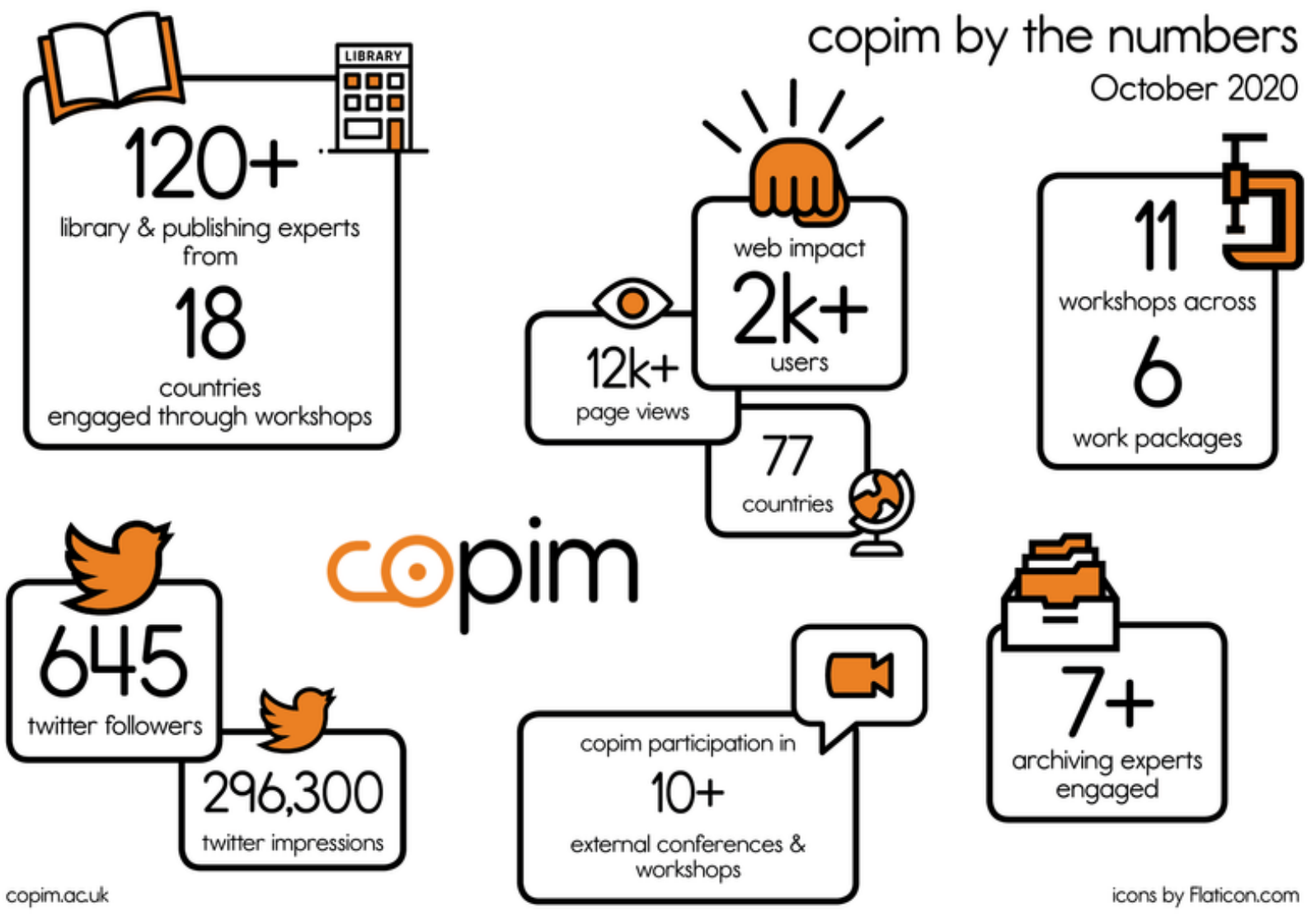




\section{Challenges}

The overall progress made during this first year is particularly impressive as the project not only had to face the typical challenges of first-year setup, but we were also faced with a set of unprecedented difficulties, including the impact of Brexit on the economy and the impact of the COVID-19 pandemic, with all its systemic consequences.

Brexit, and its impact on the economy, with the British Pound's intermittent loss in value, has particularly affected project payments to US- and EU-based partners; it has also caused uncertainties around the viability of contractual setups with international partners (EU, US), and their future sustainability due to the increased possibility of changing legislation (e.g. GDPR and continuing uncertainty around the UK's potential future non-compliance).

The impact of the COVID-19 pandemic on the Higher Education sector is becoming increasingly tangible, with already-shrinking budgets available to a sizeable portion of COPIM's stakeholders, $\underline{1}$ which in turn might mean less willingness to engage in the transformative approach that COPIM is proposing. This also impacted the project's recruitment strategy, as recruitment limitations were enforced in several partner institutions, causing delays in staffing. The pandemic also created a set of challenges for the team, including the switch to working from home and the necessity of dealing with a notable increase in care duties, which impacted on members' availability and called for a flexible approach to meeting management and general workflows in the project.

Switching from in-person stakeholder workshops to new modes of engagement via online events brought a completely new set of challenges that the team had to face. A case in point was COPIM's need to move the first cross-WP workshop that had been planned as a two-day in-person event to online at the last minute, with no benchmarks of how to facilitate such a pivot available at the time. These new modes of engagement, however, have also led to an increase in the number of workshops planned by COPIM members. In many respects, the updated mode of delivery has proven beneficial for COPIM, with increased efficiency in organising logistics and participants through a more streamlined setup also allowing the project team to include participants from a wider range of geographic locations, and further extending stakeholder engagement to regions that tend to be underrepresented in the larger OA discourse. $\underline{2}$ 
Disadvantages of this new mode of engagement include the sometimes burdensome increase of video meetings, with Zoom fatigue always looming around the corner, and the loss of rich social interaction that in-person, face-to-face meetings offer, with the corresponding lack of ability to engage more with possible stakeholders in order to foster deeper in-person networking. Nonetheless, it is safe to say that the underlying systemic problems that have become apparent during the early months of the pandemic have also brought the team to reflect more on the ways in which the project work is made discoverable and reusable in a transparent manner.

\section{Impact}

It is safe to say that the impact achieved across all work packages during this first year has exceeded the team's initial expectations. Engagement with key stakeholders (including publishers, knowledge managers, and librarians) from the UK, the United States, Europe, Africa, Australia and New Zealand has been very fruitful, and the interest in COPIM's approach from external stakeholders is mirrored in the consistently high engagement numbers that are available from the list of Outputs (see Appendix in the Annual Report) generated by the project so far.

Our Outreach programme has also been established over the course of the first year, with the number of engaged library stakeholders exceeded by more than $100 \%$ compared to our initial plan. Our dissemination Activities are now made visible both on the newly-established project website under a major .ac.uk domain, and via our $\underline{\text { Open }}$ Documentation site, with regular updates and announcements delivered via our growing Twitter account.

\section{Individual Work Package Updates}

\section{WP2. Revenue Infrastructures and Management Platform.}

WP2 is working to develop and launch a modular, scalable revenue generation platform for open access books, to be made available to publishers and libraries. As envisioned, it will be scoped and built by a team of publishers, knowledge managers, and librarians working in partnership to develop new funding channels for open access books. To that end, WP2 has been focusing on the scoping element in its first year, working to organise a range of workshops with a large variety of stakeholders from the library and publishing world, and to produce a scoping report.

The first workshop - which originally had been envisioned to take place in Cambridge, but then coincided with the pandemic turning critical in mid-March - was turned into 
an inter-WP online event, the COPIM Publishers Workshop, held on March 16. It served as an initial test bed to discuss ideas around a book publishing revenue and management platform. This was then expanded upon in three more scoping workshops held on May_13, June 16, and July_ 7, so as to be able to collate different perspectives from a variety of regions and stakeholder positions.

Two reports reflecting on the outcomes of these workshops with different regional foci have subsequently been published:

- the first report considers the specific context of the United States of America, and

- the second report reflects outcomes of the workshop held with UK stakeholders.

The list of workshops has been further extended through a partnership with the EUfunded OPERAS-P project, which has led to four more workshops in Germany (July 30) and Poland ( $\underline{\text { August } 13}$ ) as well as with stakeholders from the Nordic countries

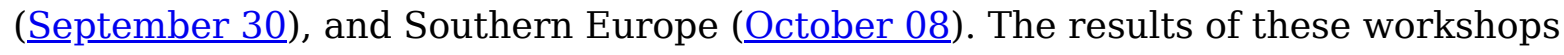
have been documented in a further collection of reports, while all of them will inform a separate scoping report currently being compiled by the COPIM-OPERAS-P liaison. This report will focus on European libraries' engagement with OA books, investigating OA book policies, funding structures, integration of OA books into library catalogues, engagement of libraries with OA in general, and a survey of scholar-/academic-/libraryled activities in the European countries represented in the study.

WP2 has drafted a first set of Design Specs for the future platform. The variety of workshops have helped to inform the scope of these specifications tremendously. These have been agreed internally by the team and, in keeping with our principles of open documentation, these will be published when final.

\section{WP3. Knowledge Exchange and Piloting Alternative Business Models}

WP3 is dedicated to knowledge exchange and transfer, as part of the project's central commitment to dissemination. It builds pathways to impact with relevant stakeholders from across the sector, including publishers (library-presses, scholar-led presses, (new) university presses), academics, learned societies, and open technology developers. To that end, WP3 has been focusing on two areas:

1. stakeholder engagement to formally scope OA business, revenue, and cost models, and documenting the research output in a report; and

2. working with university presses to launch two pilot case studies of a working sustainable OA revenue model. 
More details on both are below.

The second of these aims has seen significant progress with the recent launch of the Opening the Future pilot with the Central European University Press (CEU Press). This case study showcases an innovative revenue model to fund open access monographs at a traditional scholarly publisher, per the COPIM project brief. Working with CEU Press, WP3 have created a platform to give members access to a selection of the Press's backlist, DRM free and with perpetual access after three years. In return, the membership revenue will be used to make newly-published books openly accessible to anyone. WP3 have liaised with LYRASIS in the States who will assist with organising library participation in the programme, and have garnered support from OAPEN. The work package has also negotiated with Project MUSE who have agreed to host the books, provide MARC records, support discovery systems, and give subscribers access to COUNTER compliant statistics. Membership is open to libraries and institutions worldwide.

The initiative builds on library journal membership models such as Open Library of the Humanities and 'Subscribe to Open' such as being piloted by Annual Reviews, and also on successful book membership programmes such as those at Open Book Publishers and punctum books. In parallel, steps have been taken to investigate legal and contractual prerequisites with a second publisher which is in the final stages of talks. WP3 is hoping to announce a second pilot case study with them soon.

Regarding the first WP3 aim outlined above, a Scoping Report, $\underline{\text { Revenue Models for }}$ Open Access Monographs, published in September 2020, provides a concise analysis of the open access economic models in use today in scholarly publishing, comprising a diachronic overview and synthesis of studies published on the subject in the past ten years, and also updating these research findings to include the environment and economics of OA publishing in 2020. The scoping report is envisioned to become one component of a practical 'toolkit' that WP3 is developing to enable interested presses to convert to OA-amenable business models that then allow for the establishing of sustainable OA monograph publishing outlets.

Finally, similar to WP2, WP3's first workshop was part of an inter-WP online event led by WP5 - the COPIM Publishers Workshop, held on March 16. For WP3, this served as a valuable first scoping opportunity to engage with participants to reflect on their experiences with revenue models, but also cost models, in an open access world of books. A detailed workshop report has subsequently been published on the COPIM Open Documentation site. 


\section{WP4. Community Governance}

Work Package 4 is developing the governance procedures to support COPIM's open publication ecosystem for monographs. During the first year, WP4 has been working to establish a solid conceptual base through both research and outreach activities. It is on this base that durable organisational structures for the coordination, governance and administrative support of the project's community-owned infrastructures will be developed.

We organised a Community_Governance Workshop, facilitated by UCSB Library in close collaboration with Coventry University as an online event in May 2020. The workshop brought together governance experts, key stakeholders in OA book publishing, and representatives from allied large community-led projects, including AmeliCA, SPARC, the California Digital Library, éditions science et bien commun, and the Educopia Institute, to collaboratively explore what the governance procedures of COPIM's open publication ecosystem for monographs should look like, and to begin thinking about developing models to sustain the governance of the infrastructure as a community-based OA service organisation. A two-part report reflecting on the outcomes of this workshop has also been published.

WP4 has also successfully established a Publisher-Librarian working group - set up on the Humanities Commons platform - which is advising the project on

- a) the long-term management of consortial library funding programs;

- b) the identification and fostering of library-publisher experiments and projects that emphasise horizontal and cooperative knowledge-sharing between stakeholders (librarians, publishers, and researchers).

An outreach plan has been developed for the working group for Fall and Spring of 2020/2021, which has been shared with the participants. Internal interviews with the various COPIM WPs are also being conducted to identify the various governance needs within COPIM with respect to the infrastructures, models, and pilot cases the project is developing.

The team is working on a mapping of organisational governance models, and some first reflections have been shared in a research blogpost and as part of a series of conference papers. In addition to that, Janneke Adema and Samuel Moore have written an article on 'Scaling Small', the philosophy and organisational principle informing the COPIM project, which is currently under review at the OA journal Westminster Papers in Communication and Culture (expected publication December 2020). Sherri Barnes 
has written an essay for College and Research Libraries News on COPIM as a Transformative OA Monograph Initiative (expected publication December 2020).

\section{WP5. Building an Open Dissemination System}

Guided by the perspectives of new and emerging not-for-profit open access presses that have not yet been sufficiently integrated into existing discovery systems, knowledge bases, and supply routes, the aim of WP5 is to develop methods and systems to better integrate the catalogues of open access publishers into curated research records. The implementation of 'best practices' workflows for open access book publishers will allow their catalogues to be better integrated into the scholarly record (discoverability, reach, persistence), increasing the impact of open access books. To support this, WP5 is building an Open Dissemination System (ODS) for open access books and a shared 'best practices' digital catalogue.

Working in close collaboration with WPs 2 and 3, WP5 led the organisation of the Cambridge workshop in March. Focusing on questions of dissemination and discovery of open access books, a subsequent two-part report was published shortly after.

While the publication of WP5's research output has seen an initial delay due to the pandemic, the team decided to publish a time-stamped version of this key deliverable, while simultaneously continuing to further develop the document as the project progresses over time, and to encourage comments from the community. The benefit of this approach is two-fold: it allows for making a time-stamped document version with DOI publicly available, while the document continues to evolve on the PubPub platform and can subsequently be published again in updated form. It is representative of interative publishing workflows that are being adapted to suit the project, thus putting into practice as it does some of the principles behind COPIM.

The resulting Scoping Report discusses the distribution of books via the traditional library supply and new forms of digital dissemination before investigating questions of metadata creation, and the types of provision available for these purposes. The findings are then synthesized in a number of key recommendations for WP5 that will inform the further development of Thoth, an open metadata system that will become part of the ODS that WP5 is working on. The recommendations of the scoping report have been integrated into the GitHub development trajectory, and a public Wiki has been set up to publicly document the different platforms and outputs Thoth aims to facilitate. 
The open metadata system that will form an integral part of the ODS has begun, with a first release to be made available by November 2020. This means that work on the major Year 2 deliverable is starting well ahead of time, with development now happening iteratively and following agile code development best practice. Project code and the general progress of this development project are now made available in an open and transparent way via GitHub and the staging_website.

\section{WP6. Experimental Publishing, Re-use and Impact}

WP6 examines ways to align existing software, technologies, workflows and infrastructures for experimental publishing more closely with the workflow of open access book publishers and with the infrastructures that COPIM is endeavouring to create. It is producing a set of pilot cases of experimental books (including by ScholarLed presses Open Humanities Press and Mattering Press), which are developed with the aid of these new tools and technologies.

The work package's top priority was the successful organisation of an experimental publishing workshop. This event, hosted by Coventry University, took place in early July 2020 and brought together some of the most cutting edge open source software and platform providers working on reimagining the academic book (including Manifold, Vega, thresholds, Hybrid Publishing Group, Scalar, PubPub and the Coko Foundation) with a selection of scholar-led and new university presses (including the ScholarLed presses, UCL Press, Goldsmiths Press, and the University of Westminster Press). The workshop participants collaboratively explored

- a) how to stimulate and support the production and publication of experimental books;

- b) the main inhibitions encountered with respect to the uptake of experimental publishing and reuse;

- c) which kind of tools, platforms and infrastructures might be able to support experimental book publishing.

A two-part report reflecting on the outcomes of this workshop has also been published.

Next to the initial workshop, the work package team has conceptualised three pilot cases with Open Humanities Press (1) and Mattering Press (2), and a fourth pilot case with another press is currently being considered. The WP team will openly document the processes involved in these experiments, and the team will share their experiences via additional blog posts narrating the setting up of the first two pilot cases in the near future. 
WP6 has also been working on a two-part scoping report. The first part of this report, based on desk research, provides a typology of different types and forms of scholarly books-based on various experiments currently being conducted within academiaaccompanied by a selection of examples to illustrate each of the different types identified. The second part of this scoping report outlines the main technology and software developments currently taking place in experimental academic publishing. The report is on track to be published before the end of 2020. A separate literature review outlining inhibitions around open access book content interaction and reuse and cultural strategies has also been developed, which will feed into the research report on this topic due next year.

To support the first two Pilot Cases, technical workflows are currently being developed to incorporate existing tool and technologies into the publishers' workflows with the aid of the presses and author communities involved. This process will similarly be openly documented.

\section{WP7. Archiving and Digital Preservation}

WP7 is working to identify the key challenges associated with archiving research monographs in all their variation and complexity and develop new solutions. It began its work as scheduled six months later than the other Work Packages, in May 2020.

The work package has successfully organized its first Scoping Workshop, which took place in September in close collaboration with the Digital Preservation Coalition. It brought together participants with expertise in web archives, research data, library repositories and scholarly publishing. A report summarizing the event is currently in development.

An initial literature review of existing projects, reports, and academic work on archiving and preservation of digital books is currently being produced. Closely related to that research is the collaboration with OPERAS, with a survey led by OPERAS colleagues that has now been set up, reaching out to all 56 members of the OPERAS community, covering 17 countries. WP7 is also reaching out to more stakeholders to conduct interviews in the following weeks.

The team has already begun scoping risks and challenges for preservation, with the aim to create a draft risk register and prioritisation list of challenges. This first report will benefit from insight gained during the work package's first scoping workshop on current best practice, and possible future developments, in preserving and archiving open access books. The report is on track to be published before the end of 2020 . 


\section{And finally...}

Building on the foundational research, project management structures and outreach networks that have been successfully established in Year 1, the project is eager to continue on its path to further developing the envisioned infrastructures, pilot cases, governance structures, and outreach programmes it is set to deliver in the remaining two years of the project. Our progress will be openly documented here.

Header image by Jason Leung on Unsplash

\section{Footnotes}

1. With the Institute for Fiscal Studies estimating that UK HE's losses will be between $£ 3$ billion and $£ 19$ billion in one year: https://www.ifs.org.uk/publications/14919.

2. See e.g. Joseph, Andrew. 2015. "Scholarly Publishing in South Africa: The Global South on the Periphery”. Insights 28 (3): 62-68. DOI:

https://doi.org/10.1629/uksg.253.

Or Guédon, Jean-Claude . Open Access and the divide between "mainstream" and "peripheral" science, 2008, book chapter in: Como gerir e qualificar revistas científicas (2007, in Portuguese). https://core.ac.uk/display/11882978. and Raju, R., \& Pietersen, J. (2017). Library as Publisher: From an African Lens. Journal of Electronic Publishing, 20(2). https://doi.org/10.3998/3336451.0020.203.. 